\title{
Drug repurposing for the treatment of glioblastoma multiforme
}

\author{
Claudia Abbruzzese $^{1 \dagger}$, Silvia Matteoni ${ }^{1 \dagger}$, Michele Signore ${ }^{2}$, Luca Cardone ${ }^{3}$, Kavindra Nath ${ }^{4}$, Jerry D. Glickson ${ }^{4}$ \\ and Marco G. Paggi ${ }^{* *}$
}

\begin{abstract}
Background: Glioblastoma Multiforme is the deadliest type of brain tumor and is characterized by very poor prognosis with a limited overall survival. Current optimal therapeutic approach has essentially remained unchanged for more than a decade, consisting in maximal surgical resection followed by radiotherapy plus temozolomide.

Main body: Such a dismal patient outcome represents a compelling need for innovative and effective therapeutic approaches. Given the development of new drugs is a process presently characterized by an immense increase in costs and development time, drug repositioning, finding new uses for existing approved drugs or drug repurposing, re-use of old drugs when novel molecular findings make them attractive again, are gaining significance in clinical pharmacology, since it allows faster and less expensive delivery of potentially useful drugs from the bench to the bedside. This is quite evident in glioblastoma, where a number of old drugs is now considered for clinical use, often in association with the first-line therapeutic intervention. Interestingly, most of these medications are, or have been, widely employed for decades in non-neoplastic pathologies without relevant side effects. Now, the refinement of their molecular mechanism(s) of action through up-to-date technologies is paving the way for their use in the therapeutic approach of glioblastoma as well as other cancer types.
\end{abstract}

Short conclusion: The spiraling costs of new antineoplastic drugs and the long time required for them to reach the market demands a profoundly different approach to keep lifesaving therapies affordable for cancer patients. In this context, repurposing can represent a relatively inexpensive, safe and fast approach to glioblastoma treatment. To this end, pros and cons must be accurately considered.

Keywords: Drug repurposing, Drug repositioning, Glioblastoma multiforme, Cancer treatment, High-throughput technologies, Signal transduction, Energy metabolism

\section{Background}

Glioblastoma multiforme (GBM) is the most frequent and lethal brain tumor. Location, aggressiveness and diffuse infiltrative growth make GBM therapy extremely challenging and frequently unsuccessful. State-of-art first-line treatment of newly diagnosed cases, managed according to Stupp et al., namely maximal surgical resection followed by radiotherapy (RT) plus temozolomide (TMZ) [1], provides scarce benefits overall in clinical

\footnotetext{
* Correspondence: marco.paggi@ifo.gov.tt

${ }^{\dagger}$ Equal contributors

'Department of Research, Advanced Diagnostics and Technological Innovation, Unit of Cellular Networks and Therapeutic Targets, Proteomics Area, Regina Elena National Cancer Institute, IRCCS, Via Elio Chianesi, 53, Rome, Italy

Full list of author information is available at the end of the article
}

outcome. Indeed, median overall survival of GBM patients remains between 12 and 15 months, with a 5-year survival rate from diagnosis of less than $5 \%[2,3]$. Such a poor prognosis generates a compelling need for innovative and effective therapeutic strategies, ranging from hi-tech robotic surgery to the use of cutting edge radio- and chemotherapy.

Several novel chemotherapeutic strategies against GBM are thus frequently proposed, but current regulations for drug registration are producing an immense increase in cost and development time. At present, the pipeline from the identification of a potential molecular target up to drug registration and marketing [i.e.: discovery and screening/design, lead optimization (drug development), absorption, distribution, metabolism, excretion and toxicity (ADMET), clinical development (Phase I 
and Phase II trials), registration and marketing] ranges from 10 to 17 years [4], and the overall cost averages between 1 and 2 billion US\$ [5]. Therefore, it is not surprising that drug repositioning, finding new uses for existing drugs, or drug repurposing, a re-use of old drugs when novel molecular findings make them attractive again, are gaining importance in clinical pharmacology. Currently, repositioning and repurposing are often used as synonyms. Indeed, mining within an enormous amount of already synthesized, and often already clinically employed, compounds can realistically cut research expenses and the overall development time to bring an effective drug to the clinics. Repurposing is also considered a safer approach, due to the often available preexisting knowledge on dosage, safety and side effects of a drug, which would dramatically improve the effectiveness of a clinical trial. Thus, a rough estimate of costs and development time for repositioned drugs to reach the market is 300 million US\$ and 6 years, respectively [5], which still appears not to be satisfactory, but definitely competitive in comparison to the development $a b$ initio of new therapeutic agents.

Paradigmatic, well-known stories of success in drug repositioning include minoxidil [6], sildenafil [7, 8], thalidomide [9], azidothymidine [10] and many other compounds. For most repurposed drugs, the new therapeutic indications were understood and achieved serendipitously, although the recent-omics era is opening a door new exciting opportunities for molecular exploration of new, potential drug uses. For example, relevant molecular targets already targeted by an approved drug in the context of a specific pathology, may provide a reasonable starting point for repositioning this compound to novel therapeutic indications. This will speed up the use of potentially effective compounds and will increase the number of drugs which can be approved for use in infrequent diseases, as in rare cancer subtypes. Thus, increasing relevance is now being attributed to molecular signatures rather than to established classifications of the disease according to canonical pathological parameters.

Combining molecular signatures with drugs known to be effective in interfering with specific biochemical pathways is the ultimate challenge of molecular pharmacology, especially in the field of cancer therapy.

\section{Main text}

GBM overall poor prognosis has been the major impetus for advancing extensive molecular characterization of this disease, with the aim of addressing specific treatments according to molecular subtypes [11-13]. Benefits from the Stupp regimen, for example, are most prominent in patients with O-6-methylguanine-DNA methyltransferase (MGMT) high methylation status, and, in addition, selective therapies can be used according to the IDH1/2 mutational status $[14,15]$. Nevertheless, despite that the latest technological advancements have allowed considerable advances in molecular characterization of this form of cancer and the consequent use of novel experimental therapies, GBM prognosis remains dismal.

\section{GBM and targeted therapies}

Recent proteogenomic studies have led to the identification of diverse molecular signatures and actionable signaling pathways in GBM, such as those targeting EGFR and PI3K [3, 16]. This is in line with the notion that EGFR and other described genomic alterations, as those involving BRAF [17] or the FGFR family [18], represent valuable drug targets, but the concomitant presence of different mutations/alterations within the same tumor may generate dissimilar, non-homogeneous responses toward a specific inhibitor. Indeed, the notorious GBM heterogeneity $[19,20]$ clearly represents a condition predisposing to drug resistance and disease relapse, since these clinical events are usually driven by cell types which either have been able to escape previous therapeutic approach(es) or were generated by clonal selection of mutations as a result of a Darwinian process [21].

Targeted therapies hold an unprecedented potential, but also conceal inherent limits. The use of such innovative strategies is often associated with considerably high costs for predicting therapeutic efficacy as well as those of therapeutic procedures. Moreover, targeted drugs often lead to dramatic, although short-lived, clinical benefits only in a restricted fraction of cancer patients [22]. Such a limited favorable outcome could possibly be faced using therapeutic strategies perhaps less specific, but designed to hit general cancer cell survival pathways, such as energy metabolism, inhibition of apoptosis, autophagy and inhibition of host immune response.

\section{Approaches for drug repositioning}

Needless to say, in order to efficiently repurpose drugs that are already approved for human use, a careful selection is required, followed by thorough demonstration of their effectiveness in other biological contexts. We will now discuss some methods useful for selection of effective testing and repurposing of drugs in cancer therapy.

\section{Computational (in silico) drug repositioning}

This approach usually utilizes and elaborates public databases. Data come from basic and translational research, clinical trials, anecdotal reports regarding offlabel uses and other published human data information available. Using artificial intelligence algorithms, as well as other bioinformatics tools, investigators systematically try to identify interaction networks between drugs and protein targets. Clearly in silico drug repositioning is a 
powerful technology and carries evident significant advantages, including speed and reduced costs [23, 24].

Computational approaches require the initial generation of a drug network based on drug-drug association. Several parameters are usually employed, such as similarity in molecular structure, active catalytic sites or ligand binding sites [25]. A promising approach is the generation of drug networks based on the similarity between compounds in perturbing gene expression signatures [26, 27]. This methodology presents three main advantages: i) robustness of algorithms for gene expression data analysis; ii) cost-effectiveness; iii) availability of freely accessible resources. In addition, the transcriptional profile following drug treatment is likely to integrate multiple levels of drug response, also those elicited by secondary targets of the compound tested. A drug network allows identifying i) drugs with similar mechanism of action (MoA), the first step for a potential repurposing; ii) MoA of orphan/new drugs on the basis of shared molecular signatures; iii) drugs eliciting a signature displaying reverse features, when compared with those associated with a disease and thus potentially able to rescue it [26].

Freely available resources are ArrayExpress [28], NCBI-GEO [29] and cMap [30], all large public repositories of gene expression data. Moreover, tools such as DAVID [31], MSigDB [32] or GeneSigDB [33] allow characterizing large gene lists by using pre-defined functional terms. This strategy has been found effective also for drug repositioning [34, 35].

Recently, drug repositioning has been able to complement and assist targeted therapeutics discovery. Indeed, bio-computational approach could be successfully implemented for repurposing therapeutics able to inhibit oncogenically activated molecular pathways that are known to have a well-established impact on the molecular pathogenesis of cancer. This approach is based on modeling specific molecular alterations in cell lines, followed by the generation of an oncogene-specific gene signature. This allows the inspection of drug networkassociated signatures to reposition drugs able to "revert" the oncogenic signature, highlighting the possible role for these compounds as pathway inhibitors [27], as it has been successfully demonstrated for the identification of inhibitors of the PI3K/mTOR pathway [35, 36]. Since oncogenic pathway signatures delineate the oncogenic phenotype and represent the way to address targeted therapies [37, 38], the approach aiming at reverting oncogenic signatures could be exploited also for drug repositioning in GBM [39], also considering the profound knowledge achieved in the genomic landscape in this disease [3].

Nonetheless, before conceiving any clinical use, in vitro and mainly in vivo studies are mandatorily required in order to confirm computational predictions and design a clinical trial.

\section{Activity-based drug repositioning}

Activity-based drug repositioning essentially relies on protein target-based screenings, also in the absence of concurrent structural information. In the field of cancer therapy, molecular characterization has already allowed off-target use of specific inhibitors in pathologies different from those for which the agent was originally engineered and registered. Indeed, a paradigmatic shortcut is the discovery of actionable genomic events in a tumor type or in its subset and the straightforward possible use of a specific inhibitor already shown to be effective in other tumors carrying the same actionable mutation. For example, ALK inhibitors crizotinib or ceritinib and other second-generation inhibitors are dramatically effective in all tumors displaying dependence on an over-activated ALK kinase, usually due to the EML4-ALK rearrangement, such as anaplastic large cell lymphoma, neuroblastoma and non-small-cell lung carcinoma [40]. This represents a paradigmatic case scenario in which discoveries on the molecular basis of a disease provide an unprecedented and quick opportunity to translate research findings into new therapeutic approaches and medicines.

\section{How to expand our knowledge of a drug}

How much do we really know about the activity of a drug? Besides serendipity and apart from empirical or epidemiological observations, delving into the activity of a drug at a molecular level is now feasible. With the help of novel technologies in the field of sequencing, imaging, spectroscopy and spectrometry, basic sciences can investigate the MoA of a drug in depth and establish its potential clinical uses. The presence of quasi-unlimited experimental and computational opportunities (e.g. high-throughput platforms and high-performance computers) is timely pushing us towards the resolution of most issues related to drug repurposing. For example, only recently we were able to elucidate the real MoA of old drugs or even that of molecules belonging to the ancient pharmacopoeias (see below).

Genomics The great expectations generated by the "genomic era" have been in part fulfilled. The production and elaboration, by Next Generation Sequencing (NGS) technologies, of whole exome, transcriptomic and epigenomic data, as well as their integration, is enabling us with rational personalized treatments, even using repositioned drugs [41], in patients affected by several types of cancer [42, 43], including GBM [44].

Proteomics This approach is particularly relevant, since proteomics closely deals with the ground-level mechanisms 
underlying diseases and may provide appropriate therapeutic suggestions. Moreover, targeted proteomic profiles often demonstrate the lack of a direct relationship between static genomic data and the dynamic alterations of downstream signal transduction networks [3]. In this regard, Activity-Based Protein Profiling (ABPP), Reverse-Phase Protein microArrays (RPPA) and Magnetic Resonance Spectroscopy (MRS) are technologies that play a pivotal role in molecular pharmacology.

ABPP is capable of determining the function of several enzymes in complex biological systems using sitedirected covalent probes aimed at assessing the functional state of specific classes of enzymes [45]. ABPP is gaining importance as a uniquely powerful post-genomic method for monitoring protein function as well as the molecular effects of drugs. ABPP proposes a variety of molecular probes able to monitor several enzyme activities, e.g. kinase, protease, serine hydrolase, metalloproteinase, cysteine protease, caspase, deubiquitylase, as well as Cytochrome P450 [46]. The use of this technology is often connected with Mass Spectrometry (MS) analysis. In clinical pharmacology, ABPP is particularly useful for understanding drug-target interactions, identifying new therapeutically relevant targets as well as offtarget effects and, in addition, providing important information to assess a precise drug concentration required to hit (or not) secondary drug targets [41].

RPPA is a powerful, antibody-based technique that allows simultaneous profiling of diverse key regulatory cellular factors. RPPA was originally developed to investigate cancer cell signaling and is designed for relative and multiplexed quantification of specific cellular proteins along with their post-translational modifications [47, 48]. Opposed to MS, in RPPA complex protein matrices are immobilized onto a nitrocellulose substrate. Subsequent immunodetection, using total content as well as modification-specific antibodies, allows fine measurement of the functional state of selected cell signaling regulators. RPPA represents the state-of-art in supervised analysis of post-translational protein modifications and, in the context of repurposing, is an efficient tool to delineate the effects of drugs on several, cancer-related cellular pathways.

Essentially, while ABPP identifies the physical target(s) of a drug, RPPA evaluates the biological consequences of the drug activity. Indeed, the MoA of a drug cannot be predicted solely based on the detailed spectrum of known drug targets.

MRS is a non-invasive methodology for the analysis of flux through key pathways of cancer cell intermediary metabolism. MRS can measure flux of metabolites in glycolysis, Krebs cycle, pentose phosphate shunt, and anaplerotic pathways as pyruvate-malate shuttling, glutaminolysis, and fatty acid biosynthesis and oxidation [49]. In preclinical models, flux measurements, in the absence or presence of an interfering drug, can efficiently monitor the effect of a compound on a specific metabolic pathway in vivo. Given that this technology is non-invasive, the measurements of flux analysis can be obtained in the same subject, before and after drug administration, thus generating particularly reliable results.

In such a complex scenario, we should not ignore the possible (and frequent) repositioning of non-cancerrelated drugs in antineoplastic therapy, as assessed by various empirical and/or experimental data. Some of the following examples clearly support this assertion.

\section{Disulfiram}

Disulfiram is an ALDH1 inhibitor. Since it is able to block the production of acetic acid from ethanol, it is a medication that has been employed for decades in complete safety to treat alcohol abuse. ALDH1 is a staminal marker for GBM [50] and has been implicated in GBM resistance toward TMZ [51]. Acetate is an essential metabolite for the Krebs cycle and plays a key role in GBM and brain metastases bioenergetics [52]. It is an activator, through AMPK, of cellular energy metabolism, therefore, treatment of sensitive cells with disulfiram results in energy depletion. Disulfiram has increased activity if administered in concomitance to divalent cations (e.g. $\mathrm{Cu}$ gluconate). Of note, the effect of disulfiram appears also selectively oriented toward the stem cell compartment of a tumor [53, 54].

Interestingly, disulfiram has been recently described as an inhibitor of NF- $\mathrm{kB}[55]$ and MGMT $[56,57]$. There are open clinical trials for the use of disulfiram (plus $\mathrm{Cu}$ gluconate), in association with other drugs, in GBM therapy (Table 1).

\section{Rapamycin and derivatives}

Rapamycin (Sirolimus), was isolated in the early '70s. It was first registered as an antifungal drug and was then employed as immunosuppressant after organ transplantation and also as anticancer agent. Indeed, the unifying MoA which possibly explains rapamycin's multifaceted pharmacological spectrum of activity has been identified only recently as the inhibition of mTOR and, specifically, of the mTORC1 complex. These findings are summarized by Seto et al. [58]. In addition, a peculiar effect of rapamycin appears evident in in a mouse model of glioma-initiating cells [59].

Rapamycin also cures autoimmune lymphoproliferative syndrome (ALPS), a pre-cancerous status for which no therapy was previously available. Bride et al. report results of the first prospective multi-institutional trial of a long-term single-agent therapy for refractory cytopenias using rapamycin in 30 patients and showing remarkable efficacy in children with ALPS [60]. 
Table $1 \mathrm{NIH}$-approved clinical trials involving repurposed drugs (Metformin, Disulfiram, Chloroquine) for the treatment of GBM and other brain cancers

\begin{tabular}{|c|c|c|c|c|}
\hline NCT Number & Title of the study & Disease & Interventions & Clinical Phase \\
\hline NCT02780024 & $\begin{array}{l}\text { Metformin, Neo-adjuvant Temozolomide and } \\
\text { Hypo- Accelerated Radiotherapy Followed by } \\
\text { Adjuvant TMZ in Patients With GBM }\end{array}$ & GBM & -Drug: Metformin & Phase 2 \\
\hline NCT03151772 & $\begin{array}{l}\text { Bioavailability of Disulfiram and Metformin in } \\
\text { Glioblastomas }\end{array}$ & GBM & $\begin{array}{l}\text {-Drug: Disulfiram } \\
\text { •Drug: Metformin }\end{array}$ & Early Phase 1 \\
\hline NCT01430351 & $\begin{array}{l}\text { Phase I Factorial Trial of Temozolomide, } \\
\text { Memantine, Mefloquine, and Metformin for } \\
\text { Post-Radiation Therapy (RT) Glioblastoma } \\
\text { Multiforme (GBM) }\end{array}$ & Brain Cancer & $\begin{array}{l}\text {-Drug: Temozolomide } \\
\text {-Drug: Memantine } \\
\text {-Drug: Mefloquine } \\
\text {-Drug: Metformin }\end{array}$ & Phase 1 \\
\hline NCT02149459 & $\begin{array}{l}\text { Treatment of Recurrent Brain Tumors: Metabolic } \\
\text { Manipulation Combined With Radiotherapy }\end{array}$ & Brain Neoplasms & $\begin{array}{l}\text {-Radiation: Partial brain } \\
\text { reirradiation. } \\
\text {-Drug: Metformin } \\
\text {-Behavioral: low carbohydrate diet }\end{array}$ & Phase 1 \\
\hline NCT01777919 & $\begin{array}{l}\text { Disulfiram/Copper Combination In The Treatment } \\
\text { of Newly Diagnosed Glioblastoma Multiforme }\end{array}$ & GBM & $\begin{array}{l}\text {-Drug: Temozolomide } \\
\text {-Drug: Disulfiram } \\
\text {-Drug: Copper }\end{array}$ & Phase 2 \\
\hline NCT01907165 & $\begin{array}{l}\text { Disulfiram in Treating Patients With Glioblastoma } \\
\text { Multiforme After Radiation Therapy With Temozolomide }\end{array}$ & GBM & $\begin{array}{l}\text {-Drug: Temozolomide } \\
\text {-Drug: Disulfiram } \\
\text {-Dietary } \\
\text { Supplement: } \\
\text { Copper gluconate }\end{array}$ & Early Phase 1 \\
\hline NCT02715609 & $\begin{array}{l}\text { Disulfiram/Copper With Concurrent Radiation Therapy } \\
\text { and Temozolomide in Patients With Newly Diagnosed } \\
\text { Glioblastoma }\end{array}$ & GBM & $\begin{array}{l}\text {-Drug: Disulfiram } \\
\text {-Drug: Copper Gluconate } \\
\text {-Procedure: Surgery } \\
\text { - Radiation: Radiation } \\
\text {-Drug: Temozolomide }\end{array}$ & $\begin{array}{l}\text { Phase } 1 \\
\text { Phase } 2\end{array}$ \\
\hline NCT03151772 & $\begin{array}{l}\text { Bioavailability of Disulfiram and Metformin in } \\
\text { Glioblastomas }\end{array}$ & GBM & $\begin{array}{l}\text {-Drug: Disulfiram } \\
\text {-Drug: Metformin }\end{array}$ & Early Phase 1 \\
\hline NCT03034135 & $\begin{array}{l}\text { Safety, Tolerability and Efficacy of Disulfiram and } \\
\text { Copper Gluconate in Recurrent Glioblastoma }\end{array}$ & Recurrent GBM & -Drug: Disulfiram/Copper & Phase 2 \\
\hline NCT02678975 & Disulfiram in Recurrent Glioblastoma & Glioma and GBM & $\begin{array}{l}\text {-Drug: Disulfiram } \\
\text {-Dietary Supplement: Copper } \\
\text {-Drug: Alkylating agents }\end{array}$ & $\begin{array}{l}\text { Phase } 2 \\
\text { Phase } 3\end{array}$ \\
\hline NCT02770378 & $\begin{array}{l}\text { A Proof-of-concept Clinical Trial Assessing the Safety } \\
\text { of the Coordinated Undermining of Survival Paths by } \\
9 \text { Repurposed Drugs Combined With } \\
\text { Metronomic Temozolomide (CUSP9v3 Treatment } \\
\text { Protocol) for Recurrent Glioblastoma }\end{array}$ & GBM & $\begin{array}{l}\text {-Drug: Temozolomide } \\
\text {-Drug: Aprepitant } \\
\text {-Drug: Minocycline } \\
\text {-Drug: Disulfiram } \\
\text {-Drug: Celecoxib } \\
\text {-Drug: Sertraline } \\
\text {-Drug: Captopril } \\
\text {-Drug: Itraconazole } \\
\text {-Drug: Ritonavir } \\
\text {-Drug: Auranofin }\end{array}$ & Phase 1 \\
\hline NCT00224978 & Chloroquine for Treatment of Glioblastoma Multiforme & GBM & •Drug: Chloroquine & Phase 3 \\
\hline NCT02378532 & $\begin{array}{l}\text { The Addition of Chloroquine to Chemoradiation for } \\
\text { Glioblastoma }\end{array}$ & GBM & $\begin{array}{l}\text {-Drug: Chloroquine } \\
\text {-Radiation: Radiotherapy } \\
\text {-Drug: Temozolomide }\end{array}$ & Phase 1 \\
\hline NCT02432417 & $\begin{array}{l}\text { The Addition of Chloroquine to Chemoradiation for } \\
\text { Glioblastoma }\end{array}$ & $\begin{array}{l}\text { High-grade } \\
\text { astrocytoma } \\
\text { GBM }\end{array}$ & -Drug: Chloroquine & Phase 2 \\
\hline
\end{tabular}

Source: https://clinicaltrials.gov/

Several rapamycin derivatives (rapalogues) have been synthesized, e.g. temsirolimus, everolimus and ridaforolimus. Recently, rapamycin and its derivatives are gaining considerable interest due to their involvement in processes decelerating geroconversion, i.e. cellular ageing, [61, 62] and are also employed in
Phase 2 clinical trials involving GBM patients showing therapeutic benefits in subjects whose tumor displays high mTORC1 activity [63].At present (November 2017), the site https://clinicaltrials.gov lists $>30$ clinical trials involving rapamycin or its derivatives in GBM and, more generically, in brain and 
CNS cancer therapy. Due to their number, these clinical trials will not be listed in Table 1 .

\section{Metformin}

Metformin is the most widely used oral antidiabetic drug and belongs, along with phenformin and buformin, to the group of biguanides. This drug has low and infrequent side effects (lactic acidosis in predisposed subjects) and, as a drug safety criterion, is now considered for its potential use in cancer chemoprevention [64-66]. Metformin activates AMPK and inhibits mTORC1 activity $[67,68]$, mainly due to its role in impeding the mitochondrial respiratory chain, thus increasing cytosolic AMP concentration. In this way, metformin reduces energy efficiency, thus increasing glucose consumption, which is, together with the inhibition of hepatic gluconeogenesis, the key mechanism responsible for its ability to lower glycaemia in diabetic patients. Recently, a set of kinases have been identified as potential metformin targets, including SGK1 and EGFR, but not AKT1 [69].

Metformin reduces aging in $C$. elegans, increasing its lifespan [64], while combined administration of metformin and rapamycin has been shown to be effective in increasing lifespan in mice [70].

The use of metformin at higher than conventional doses for antidiabetic therapy is postulated as a tool for reprogramming cancer cell metabolism, possibly providing new perspectives for synthetic lethality through intelligent drug combinations. Along similar lines, metformin could be used to target cells characterized by hypersensitivity to energetic stress [65], and is now finding its own role as an adjuvant in cancer therapy [71]. Currently, clinical trials are active for its use, in association with other drugs, in GBM therapy (Table 1).

\section{Lonidamine}

In the late 1980s, lonidamine (LND, also known as AF1890), a reversible inhibitor of spermatogenesis [72], was widely employed in clinical trials for cancer therapy in combination with several anticancer drugs and/or radiation (for a review, see [73]). LND is characterized by relatively mild side effects that do not overlap with those related to conventional cytostatic therapies [74]. Its toxicity does not involve bone marrow, but myalgia appears as the most relevant and common side effect [74], likely related to the proton-linked Monocarboxylate Transporter (MCT) inhibition and consequent lactate accumulation in myocytes. In male patients, reversible azoospermia should be taken into account.

During its clinical use as an anticancer drug in combination with other therapeutic regimens, LND exhibited encouraging results in some contexts, such as Head \& Neck cancer [74] and brain tumors [75, 76]. The drug was defined "unconventional" because the target of LND was at the level of energy metabolism, selectively producing drastic energy depletion in cancer cells in vitro and in vivo [73].

The rationale underlying the repurposing of LND originates from a more accurate and intriguing identification of its MoA. Now, further evidence, using the most recent technologies, mainly MRS, refines the MoA of the drug, showing that LND concurrently inhibits L-lactic acid efflux from cells mediated by the MCT family proteins. In addition, recent data on Mitochondrial Pyruvate Carrier (MPC) and complex II inhibition [77, 78] strongly support previous reports on the decrease of oxygen consumption by the drug [79, 80]. LND has also been demonstrated to elicit a cytotoxic autophagic response in GBM cells [81].

Used as a single agent, LND does not efficiently impede cancer cell growth, both in vitro and in vivo, being its effects transient and reversible. Nevertheless, when administered in association with other anticancer radioor chemotherapeutic schemes, LND interferes with the survival pathways from which cancer cells are dependent. This is essentially due to the potent ATP depletion and acidification of the intracellular environment produced by LND, both phenomena being far more intense in cancer than in normal tissues [82].

Interestingly, similar to metformin, LND has been demonstrated to reduce C. elegans aging [83].

\section{Chloroquine and related antimalarial drugs}

This class of drugs has been widely used for decades in malaria prevention and therapy. These molecules are effective in blocking $P$. falciparum life cycle and are relatively well-tolerated. Recently, antimalarial drugs are also considered in cancer chemotherapy [84]. Indeed, a key role has been attributed to these drugs in inhibiting the late steps of autophagy. Autophagy is a homeostatic intracellular process which enables the degradation of old or damaged intracellular organelles. In normal cells, autophagy acts as a type of rejuvenation procedure, while in cancer cells, and mainly cancer stem cells, it provides a noticeable and self-generated source of energy [85]. When the autophagic process is evoked, the final cellular outcome can be quite diverse, ranging from a cytotoxic effect, eventually culminating in cell death, to an increase in survival capabilities in an unfavorable environment. In tumor cells, autophagy is regarded as a cytoprotective adaptive response to radio- or chemotherapy, particularly in cancer stem cells [86-88]. Basically, chloroquine and related drugs lead to accumulation of non-functional autophagic vacuoles, thus inhibiting autophagy at its late stages [89, 90]. Indeed, chloroquine has been demonstrated effective in inhibiting cancer stem cell growth in triple negative breast cancer [91] as well as in other neoplastic pathologies $[92,93]$. On this 
basis, antimalarial drugs have been shown to be effective in inhibiting glioma and GBM cell growth in vitro and in vivo in combination with TMZ [94-96], and several clinical trials have been conducted [93, 97-99]. In the context of brain tumors, the derivative quinacrine, employed in the therapy of cerebral malaria, should be also considered for clinical experimentation, due to its elevated permeability through the Blood-Brain Barrier [100]. A number of clinical trials involving the use of chloroquine and related compounds in GBM therapeutic schemes are listed in Table 1.

\section{Chlorpromazine and other dopamine receptors inhibitors} Chlorpromazine (CPZ) belongs to the class of tricyclic antipsychotic agents. It is a medication used since the '50s to cure psychotic disorders. CPZ acts as an antagonist on different postsynaptic and presynaptic receptors, mainly dopamine receptors D2 (DRD2). Recently CPZ has been demonstrated to have at least two further MoAs, which can suggest its use, alone or in combination, in cancer treatment. Indeed, $\mathrm{CPZ}$ acts as: a) a potent and specific inhibitor of the mitotic kinesin KSP/ Eg5, thus hindering cancer cell proliferation via mitotic arrest and accumulation of defective, monopolar spindles [101] and b) an inhibitor of the AKT/mTOR signal transduction axis in human glioma cells, thus eliciting autophagic cell death [102]. At present, there are no clinical trials involving the use of chlorpromazine in the treatment of GBM or other brain cancers. Of note, dopamine receptor D4 (DRD4) inhibitors, e.g. fananserin, are presently under investigation for their reported ability to selectively induce autophagy in GBM stem cells, with no detectable toxicity in fibroblasts and only minor effects in normal neural stem cells [103]. Such specificity has been interpreted as an ancestral response to neurotransmitters that could be retained by GBMderived neural stem cells.

\section{Conclusions}

Although the drugs listed above are admittedly limited in number, most of them are apparently able to interfere with critical signal transduction and/or energy metabolism pathway.

The activity of the mTOR complexes 1 and 2 is pivotal for cancer cells, and mTORC1 inhibitors play a key role in restraining cancer cell growth in GBM [104]. Here, a subset of drug classes candidate for repositioning in cancer therapy, e.g. rapamycin plus its derivatives, metformin plus other oral antidiabetic drugs and chlorpromazine, are known to interfere with the AMPK/mTORC1 axis, which is accountable for most of their cancer cell growth inhibitory effects. On the other hand, GBM cells have been demonstrated to withstand mTOR inhibition by activating glutamine metabolism via glutaminase (GLS) and combined
mTOR and GLS inhibition results in synergistic tumor growth inhibition in a GBM preclinical setting [105].

Now, a well-known characteristic of most tumors, including GBM, is metabolic reprogramming [87, 106], historically epitomized by elevated glucose consumption, even in the presence of suitable, physiological oxygen concentrations (Warburg effect) [107, 108]. Indeed, GBMs display disproportionately high glycolytic rates, and this metabolic pathway plays a key role in ATP production [109-111]. Of note, increased energy metabolism, a highly recognized hallmark of cancer [112], appears as a common vulnerable target in a disease, GBM, that by definition manifests itself in so many different forms.

A straightforward link between energy metabolism and the autophagy suppressor mTORC1, is hexokinase II (HK-II), the rate-limiting enzyme that catalyzes the first step of glycolysis. In response to glucose deprivation, HK-II binds physically to mTORC1, thus decreasing its activity and positively regulating protective autophagy. [113]. In cancer cells, the cellular energy sensor AMPK, which plays a pivotal role in this process, is considered a key target for inhibiting the autophagybased cancer cell survival, also in GBM and other gliomas [59, 114, 115].

The medications described above, far from being target-specific drugs, can rather be considered as a means of "less targeted" therapeutic strategy designed to hit fundamental cancer cell dependencies. Considering the well-known heterogeneity of GBM, such an approach holds great potential, since administration of the aforementioned drugs, in association with the current therapeutic options, could definitely hamper diverse, ground-level cancer cell survival mechanisms, thus providing an incisive strategy for GBM treatment that hinders the selection and subsequent enrichment of resistant cell clones.

We must emphasize that all these medications are essentially well tolerated and, when used for other pathologies, have not been historically involved in hazardous side effects in patients. Possible reasons behind this could be the high sensitivity of cancer cells toward these drugs, based on differential metabolic needs of the cancer phenotype (see above), but also the fact that, in other pathologies the dosage for such drugs could be potentially lower than those required to significantly affect cancer cells [65].

Most of the data here described for these drugs clearly highlight the need for exhaustive basic and translational research to elucidate often poorly understood biological mechanisms underlying the effect of a medication. This is a mandatory step in order to allow the translation to clinical application. Current knowledge demonstrates that often it took decades or also centuries to unravel 
the full complexity of the interplay between a drug and biological systems. At this point, basic and preclinical research can generate proof-of-concept results to stimulate and promote the generation of robust proof-of-concept clinical trials.

\section{Advantages of drug repurposing}

It is important to note that drugs still under patent, but shelved after unsuccessful or only partially successful clinical trials, are amenable to repurposing. Resources have already been spent to develop these drugs and their resuscitation for similar or novel indications can lead to cost-savings and avoidance of risks related to drug development. Indeed, the knowledge of their well-investigated pharmacokinetic and pharmacodynamic characteristics can spare most of the studies directed to assess drug dosage, safety and side effects.

In addition to the above noted advantages of repurposed drugs to diminish expenses and development time to effectively reach the bedside, repurposing should be considered an invaluable opportunity to treat patients when there is no approved therapy or when a patient has exhausted all available treatment options.

\section{Obstacles to drug repurposing}

Another common characteristic shared by most of these medications is that all of them are inexpensive drugs for which patents have not been submitted, have expired or are about to expire, thus making them lacking of monetary incentives for their off-target development. This is paradoxically an obstacle, making it difficult to obtain funding for investigative research, unless the original molecule is not modified; but this can no longer be referred to as repurposing. There are also the so-called "financial orphan drugs", for which evidence of safety and efficacy has been envisaged, but no clinical trials can be easily conducted, again mostly due to the absence of financial support. As an example, our group is working on an interesting but not patented small molecule, the kinase inhibitor SI113. This molecule, from preclinical in vivo results, holds great promises in cancer combined treatment, also in GBM [116, 117], but lacks of the financial support needed for clinical experimentation.

Finally, basic and translational research for drug repurposing or orphan drugs should be funded ideally by charitable or government agencies. Valid opportunities in this field are offered by the NIH NCATS program (https://ncats.nih.gov/) or the UK Medical Research Council (MRC; https://www.mrc.ac.uk/). Other countries are also promoting basic, translational and clinical research on drug repurposing.

We strongly encourage intelligent and motivated laboratory and clinical investigations aimed at repurposing old drugs. In this context, funding agencies should be encouraged to support this research, considering the spiraling costs of novel anticancer medications and the consequent non-availability for a great number of patients. Research on repurposed drugs can thus represents a less expensive, safer and often immediately available approach to GBM treatment, as well as in other cancer pathologies, also when further lines of treatment are unavailable or unsatisfactory.

\begin{abstract}
Acknowledgements
The authors wish to thank Tania Merlino for proofreading the manuscript.

Funding

Funding in our laboratories is provided by: "Ricerca Corrente IRE" (MGP); NIH grants R01-CA1219544 (JDG) and R01-CA172820 (JDG).

Availability of data and materials

Not applicable.

\section{Authors' contributions}

CA: contributed to bibliographic retrieval, critical analysis and manuscript drafting. SM: contributed to bibliographic retrieval, critical analysis and manuscript drafting. MS: contributed to the activity-based drug repositioning section, mainly RPPA. LC: contributed to the in silico drug repositioning section. KN: contributed to the activity-based drug repositioning section, mainly in the field of energy metabolism. JDG: contributed to the activity-based drug repositioning section, mainly in the field of energy metabolism, and critical revision of the whole manuscript. MGP: contributed to bibliographic retrieval, critical analysis, manuscript drafting and overall critical revision of the whole manuscript. All authors read and approved the final manuscript.
\end{abstract}

Ethics approval and consent to participate

Not applicable.

\section{Consent for publication}

All authors are aware of and agree to the content of this manuscript and to being listed as an author. No authors have any conflict of interest on the topic of the present manuscript.

\section{Competing interests}

The authors declare that they have no competing interests.

\section{Publisher's Note}

Springer Nature remains neutral with regard to jurisdictional claims in published maps and institutional affiliations.

\section{Author details}

'Department of Research, Advanced Diagnostics and Technological Innovation, Unit of Cellular Networks and Therapeutic Targets, Proteomics Area, Regina Elena National Cancer Institute, IRCCS, Via Elio Chianesi, 53, Rome, Italy. ${ }^{2}$ RPPA Unit, Proteomics Area, Core Facilities, Istituto Superiore di Sanità, Rome, Italy. ${ }^{3}$ Department of Research, Advanced Diagnostics and Technological Innovation, Unit of Cellular Networks and Therapeutic Targets, Regina Elena National Cancer Institute, IRCCS, Rome, Italy. ${ }^{4}$ Laboratory of Molecular Imaging, Department of Radiology, University of Pennsylvania Perelman School of Medicine, Philadelphia, PA, USA.

Received: 9 November 2017 Accepted: 17 November 2017 Published online: 28 November 2017

References

1. Stupp R, Mason WP, van den Bent MJ, Weller M, Fisher B, Taphoorn MJ, et al. Radiotherapy plus concomitant and adjuvant temozolomide for glioblastoma. N Engl J Med. 2005;352(10):987-96. doi: 10.1056/ NEJMoa043330.

2. Cloughesy TF, Cavenee WK, Mischel PS. Glioblastoma: from molecular pathology to targeted treatment. Annu Rev Pathol. 2014;9:1-25. doi: 10. 1146/annurev-pathol-011110-130324. 
3. Brennan CW, Verhaak RG, McKenna A, Campos B, Noushmehr H, Salama SR, et al. The somatic genomic landscape of glioblastoma. Cell. 2013;155(2): 462-77. doi: 10.1016/j.cell.2013.09.034

4. Ashburn TT, Thor KB. Drug repositioning: identifying and developing new uses for existing drugs. Nat Rev Drug Discov. 2004;3(8):673-83. doi: 10.1038/nrd1468.

5. Nosengo N. Can you teach old drugs new tricks? Nature. 2016;534(7607): 314-6. doi: 10.1038/534314a.

6. Zappacosta AR. Reversal of baldness in patient receiving minoxidil for hypertension. N Engl J Med. 1980;303(25):1480-1.

7. Galie N, Ghofrani HA, Torbicki A, Barst RJ, Rubin LJ, Badesch D, et al. Sildenafil citrate therapy for pulmonary arterial hypertension. N Engl J Med. 2005:353(20):2148-57. doi: 10.1056/NEJMoa050010.

8. Goldstein I, Lue TF, Padma-Nathan H, Rosen RC, Steers WD, Wicker PA. Oral sildenafil in the treatment of erectile dysfunction. Sildenafil study group. N Engl J Med. 1998;338(20):1397-404. doi: 10.1056/NEJM199805143382001.

9. Singhal S, Mehta J, Desikan R, Ayers D, Roberson P, Eddlemon P, et al. Antitumor activity of thalidomide in refractory multiple myeloma. $N$ Engl J Med. 1999;341(21):1565-71. doi: 10.1056/NEJM199911183412102.

10. Furman PA, Fyfe JA, St Clair MH, Weinhold K, Rideout JL, Freeman GA, et al. Phosphorylation of 3'-azido-3'-deoxythymidine and selective interaction of the $5^{\prime}$-triphosphate with human immunodeficiency virus reverse transcriptase. Proc Natl Acad Sci U S A. 1986;83(21):8333-7.

11. Foote MB, Papadopoulos N, Diaz LA Jr. Genetic classification of gliomas: refining histopathology. Cancer Cell. 2015;28(1):9-11. doi: 10.1016/j.ccell.2015.06.014.

12. Frattini V, Trifonov V, Chan JM, Castano A, Lia M, Abate F, et al. The integrated landscape of driver genomic alterations in glioblastoma. Nat Genet. 2013:45(10):1141-9. doi: 10.1038/ng.2734.

13. Ludwig K, Kornblum HI. Molecular markers in glioma. J Neuro-Oncol. 2017; doi: 10.1007/s11060-017-2379-y.

14. Rohle D, Popovici-Muller J, Palaskas N, Turcan S, Grommes C, Campos C, et al. An inhibitor of mutant IDH1 delays growth and promotes differentiation of glioma cells. Science. 2013;340(6132):626-30. doi: 10.1126/science.1236062.

15. Di Stefano AL, Fucci A, Frattini V, Labussiere M, Mokhtari K, Zoppoli P, et al. Detection, characterization, and inhibition of FGFR-TACC fusions in IDH wild-type glioma. Clin Cancer Res. 2015;21(14):3307-17. doi: 10.1158/10780432.CCR-14-2199.

16. Zhang Y, Kwok-Shing Ng P, Kucherlapati M, Chen F, Liu Y, Tsang YH, et al. A pan-cancer Proteogenomic atlas of PI3K/AKT/mTOR pathway alterations. Cancer Cell. 2017;31(6):820-832 e3. doi: 10.1016/j.ccell.2017.04.013.

17. Lerner RG, Grossauer S, Kadkhodaei B, Meyers I, Sidorov M, Koeck K, et al. Targeting a Plk1-controlled polarity checkpoint in therapy-resistant glioblastoma-propagating cells. Cancer Res. 2015;75(24):5355-66. doi: 10. 1158/0008-5472.CAN-14-3689.

18. Singh D, Chan JM, Zoppoli P, Niola F, Sullivan R, Castano A, et al. Transforming fusions of FGFR and TACC genes in human glioblastoma. Science. 2012;337(6099):1231-5. doi: 10.1126/science.1220834.

19. Furnari FB, Cloughesy TF, Cavenee WK, Mischel PS. Heterogeneity of epidermal growth factor receptor signalling networks in glioblastoma. Nat Rev Cancer. 2015;15(5):302-10. doi: 10.1038/nrc3918.

20. Meyer M, Reimand J, Lan X, Head R, Zhu X, Kushida M, et al. Single cellderived clonal analysis of human glioblastoma links functional and genomic heterogeneity. Proc Natl Acad Sci U S A. 2015;112(3):851-6. doi: 10.1073/ pnas.1320611111.

21. Gerlinger M, Rowan AJ, Horswell S, Larkin J, Endesfelder D, Gronroos E, et al. Intratumor heterogeneity and branched evolution revealed by multiregion sequencing. N Engl J Med. 2012;366(10):883-92. doi: 10.1056/NEJMoa1113205.

22. Prasad V. Perspective: the precision-oncology illusion. Nature. 2016; 537(7619):S63. doi: 10.1038/537563a.

23. Liu Z, Fang $H$, Reagan $\mathrm{K}, \mathrm{Xu} X$, Mendrick DL, Slikker W Jr, et al. In silico drug repositioning: what we need to know. Drug Discov Today. 2013;18(3-4): 110-5. doi: 10.1016/j.drudis.2012.08.005.

24. Patel MN, Halling-Brown MD, Tym JE, Workman P, Al-Lazikani B. Objective assessment of cancer genes for drug discovery. Nat Rev Drug Discov. 2013; 12(1):35-50. doi: 10.1038/nrd3913.

25. Berger Sl, lyengar R. Network analyses in systems pharmacology. Bioinformatics. 2009;25(19):2466-72. doi: 10.1093/bioinformatics/btp465.

26. Iorio F, Rittman T, Ge H, Menden M, Saez-Rodriguez J. Transcriptional data: a new gateway to drug repositioning? Drug Discov Today. 2013;18(7-8):3507. doi: 10.1016/j.drudis.2012.07.014.

27. Cardone L. Biocomputing drug repurposing toward targeted therapies. Aging (Albany NY). 2016:8(11):2609-10. 10.18632/aging.101135.
28. Parkinson H, Sarkans U, Kolesnikov N, Abeygunawardena N, Burdett T, Dylag $\mathrm{M}$, et al. ArrayExpress update-an archive of microarray and high-throughput sequencing-based functional genomics experiments. Nucleic Acids Res. 2011;39(Database):D1002-4. doi: 10.1093/nar/gkq1040.

29. Barrett T, Suzek TO, Troup DB, Wilhite SE, Ngau WC, Ledoux P, et al. NCBI GEO: mining millions of expression profiles-database and tools. Nucleic Acids Res. 2005;33(Database issue):D562-6. doi: 10.1093/nar/gki022.

30. Lamb J, Crawford ED, Peck D, Modell JW, Blat IC, Wrobel MJ, et al. The connectivity map: using gene-expression signatures to connect small molecules, genes, and disease. Science. 2006;313(5795):1929-35. doi: 10. 1126/science.1132939.

31. Huang DW, Sherman BT, Lempicki RA. Systematic and integrative analysis of large gene lists using DAVID bioinformatics resources. Nat Protocols. 2008; 4(1):44-57. doi: 10.1038/nprot.2008.211.

32. Subramanian A, Tamayo P, Mootha VK, Mukherjee S, Ebert BL, Gillette MA, et al. Gene set enrichment analysis: a knowledge-based approach for interpreting genome-wide expression profiles. Proc Natl Acad Sci U S A. 2005;102(43):15545-50. doi: 10.1073/pnas.0506580102.

33. Culhane AC, Schwarzl T, Sultana R, Picard KC, Picard SC, Lu TH, et al. GeneSigDB-a curated database of gene expression signatures. Nucleic Acids Res. 2010;38(Database issue):D716-25. doi: 10.1093/nar/gkp1015.

34. Iorio F, Bosotti R, Scacheri E, Belcastro V, Mithbaokar P, Ferriero R, et al. Discovery of drug mode of action and drug repositioning from transcriptional responses. Proc Natl Acad Sci U S A. 2010;107(33):14621-6. doi: 10.1073/pnas.1000138107.

35. Carrella D, Manni I, Tumaini B, Dattilo R, Papaccio F, Mutarelli M, et al. Computational drugs repositioning identifies inhibitors of oncogenic PI3K AKT/P70S6K-dependent pathways among FDA-approved compounds. Oncotarget. 2016;7(37):58743-58. 10.18632/oncotarget.11318.

36. Ghosh JC, Siegelin MD, Vaira V, Faversani A, Tavecchio M, Chae YC, et al. Adaptive mitochondrial reprogramming and resistance to PI3K therapy. J Natl Cancer Inst. 2015;107(3) doi: 10.1093/jnci/dju502.

37. Nevins JR, Potti A. Mining gene expression profiles: expression signatures as cancer phenotypes. Nat Rev Genet. 2007;8(8):601-9. doi: 10.1038/nrg2137.

38. Bild AH, Yao G, Chang JT, Wang Q, Potti A, Chasse D, et al. Oncogenic pathway signatures in human cancers as a guide to targeted therapies. Nature. 2006;439(7074):353-7. doi: 10.1038/nature04296.

39. Zhang Y, Cruickshanks N, Yuan F, Wang B, Pahuski M, Wulfkuhle J, et al. Targetable T-type calcium channels drive glioblastoma. Cancer Res. 2017; 77(13):3479-90. doi: 10.1158/0008-5472.CAN-16-2347.

40. Gerber DE, Minna JD. ALK inhibition for non-small cell lung cancer: from discovery to therapy in record time. Cancer Cell. 2010;18(6):548-51. doi: 10. 1016/j.ccr.2010.11.033

41. Jones LH, Neubert H. Clinical chemoproteomics-opportunities and obstacles. Sci Transl Med. 2017:9(386) doi: 10.1126/scitranslmed.aaf7951.

42. Cheng $\mathrm{F}$, Hong $\mathrm{H}$, Yang $\mathrm{S}$, Wei Y. Individualized network-based drug repositioning infrastructure for precision oncology in the panomics era. Brief Bioinform. 2017;18(4):682-97. doi: 10.1093/bib/bbw051.

43. McCarthy JJ, McLeod HL, Ginsburg GS. Genomic medicine: a decade of successes, challenges, and opportunities. Sci Transl Med. 2013;5(189):189sr4. doi: 10.1126/scitransImed.3005785.

44. Molenaar RJ, Coelen RJ, Khurshed M, Roos E, Caan MW, van Linde ME, et al. Study protocol of a phase IB/I clinical trial of metformin and chloroquine in patients with IDH1-mutated or IDH2-mutated solid tumours. BMJ Open. 2017;7(6):e014961. doi: 10.1136/bmjopen-2016-014961.

45. Chen X, Wong YK, Wang J, Zhang J, Lee YM, Shen HM, et al. Target identification with quantitative activity based protein profiling (ABPP). Proteomics. 2017;17(3-4) doi: 10.1002/pmic.201600212.

46. Barglow KT, Cravatt BF. Activity-based protein profiling for the functional annotation of enzymes. Nat Methods. 2007;4(10):822-7. doi: 10.1038/nmeth1092.

47. Pierobon M, Wulfkuhle J, Liotta L, Petricoin E. Application of molecular technologies for phosphoproteomic analysis of clinical samples. Oncogene. 2015;34(7):805-14. doi: 10.1038/onc.2014.16.

48. Pierobon M, VanMeter AJ, Moroni N, Galdi F, Petricoin EF III. Reverse-phase protein microarrays. Methods MolBiol. 2012;823:215-35. doi: 10.1007/978-160327-216-2 14

49. Shestov AA, Lee SC, Nath K, Guo L, Nelson DS, Roman JC, et al. (13)C MRS and LC-MS flux analysis of tumor intermediary metabolism. Front Oncol. 2016;6:135. doi: 10.3389/fonc.2016.00135.

50. Rasper M, Schafer A, Piontek G, Teufel J, Brockhoff G, Ringel F, et al. Aldehyde dehydrogenase 1 positive glioblastoma cells show brain tumor 
stem cell capacity. Neuro-Oncology. 2010;12(10):1024-33. doi: 10.1093/ neuonc/noq070.

51. Schafer A, Teufel J, Ringel F, Bettstetter M, Hoepner I, Rasper M, et al. Aldehyde dehydrogenase 1A1-a new mediator of resistance to temozolomide in glioblastoma. Neuro-Oncology. 2012;14(12):1452-64. doi: 10.1093/neuonc/nos270.

52. Mashimo T, Pichumani K, Vemireddy V, Hatanpaa KJ, Singh DK, Sirasanagandla $\mathrm{S}$, et al. Acetate is a bioenergetic substrate for human glioblastoma and brain metastases. Cell. 2014;159(7):1603-14. doi: 10.1016/j. cell.2014.11.025

53. Triscott J, Rose Pambid M, Dunn SE. Concise review: bullseye: targeting cancer stem cells to improve the treatment of gliomas by repurposing disulfiram. Stem Cells. 2015;33(4):1042-6. doi: 10.1002/stem.1956.

54. Lun X, Wells JC, Grinshtein N, King JC, Hao X, Dang NH, et al. Disulfiram when combined with copper enhances the therapeutic effects of temozolomide for the treatment of glioblastoma. Clin Cancer Res. 2016; doi: 10.1158/1078-0432.CCR-15-1798.

55. Liu P, Brown S, Goktug T, Channathodiyil P, Kannappan V, Hugnot JP, et al. Cytotoxic effect of disulfiram/copper on human glioblastoma cell lines and ALDH-positive cancer-stem-like cells. Br J Cancer. 2012;107(9):1488-97. doi: 10.1038/bjc.2012.442

56. Triscott J, Lee C, Hu K, Fotovati A, Berns R, Pambid M, et al. Disulfiram, a drug widely used to control alcoholism, suppresses the self-renewal of glioblastoma and over-rides resistance to temozolomide. Oncotarget. 2012; 3(10):1112-23. 10.18632/oncotarget.604.

57. Paranjpe A, Zhang R, Ali-Osman F, Bobustuc GC, Srivenugopal KS. Disulfiram is a direct and potent inhibitor of human O6-methylguanine-DNA methyltransferase (MGMT) in brain tumor cells and mouse brain and markedly increases the alkylating DNA damage. Carcinogenesis. 2014;35(3): 692-702. doi: 10.1093/carcin/bgt366.

58. Seto B. Rapamycin and mTOR: a serendipitous discovery and implications for breast cancer. Clin Transl Med. 2012;1(1):29. https://doi.org/10.1186/ 2001-1326-1-29.

59. Hegazy AM, Yamada D, Kobayashi M, Kohno S, Ueno M, Ali MA, et al. Therapeutic strategy for targeting aggressive malignant gliomas by disrupting their energy balance. J Biol Chem. 2016; doi: 10.1074/jbc.M116.734756.

60. Bride KL, Vincent T, Smith-Whitley K, Lambert MP, Bleesing JJ, Seif AE, et al. Sirolimus is effective in relapsed/refractory autoimmune cytopenias: results of a prospective multi-institutional trial. Blood. 2016;127(1):17-28. doi: 10 1182/blood-2015-07-657981.

61. Johnson SC, Rabinovitch PS, Kaeberlein M. mTOR is a key modulator of ageing and age-related disease. Nature. 2013;493(7432):338-45. doi: 10. 1038/nature11861.

62. Lamming DW, Ye L, Sabatini DM, Baur JA. Rapalogs and mTOR inhibitors as anti-aging therapeutics. J Clin Invest. 2013;123(3):980-9. doi: 10.1172/ JCl64099.

63. Wick W, Gorlia T, Bady P, Platten M, van den Bent MJ, Taphoorn MJ, et al. Phase II study of radiotherapy and Temsirolimus versus Radiochemotherapy with Temozolomide in patients with newly diagnosed glioblastoma without MGMT promoter Hypermethylation (EORTC 26082). Clin Cancer Res. 2016; 22(19):4797-806. doi: 10.1158/1078-0432.CCR-15-3153.

64. Wu L, Zhou B, Oshiro-Rapley N, Li M, Paulo JA, Webster CM, et al. An ancient, unified mechanism for metformin growth inhibition in C. Elegans and cancer. Cell. 2016;167(7):1705-1718 e13. doi: 10.1016/j.cell.2016.11.055.

65. Pollak MN. Investigating metformin for cancer prevention and treatment: the end of the beginning. Cancer Discov. 2012;2(9):778-90. doi: 10.1158/ 2159-8290.CD-12-0263.

66. Morales DR, Morris AD. Metformin in cancer treatment and prevention. Annu Rev Med. 2015:66:17-29. doi: 10.1146/annurev-med-062613-093128.

67. Howell JJ, Hellberg K, Turner M, Talbott G, Kolar MJ, Ross DS, et al. Metformin inhibits hepatic mTORC1 signaling via dose-dependent mechanisms involving AMPK and the TSC complex. Cell Metab. 2017;25(2): 463-71. doi: 10.1016/j.cmet.2016.12.009

68. Pernicova I, Korbonits M. Metformin-mode of action and clinical implications for diabetes and cancer. Nat Rev Endocrinol. 2014;10(3):143-56. doi: 10.1038/nrendo.2013.256

69. Hart T, Dider S, Han W, Xu H, Zhao Z, Xie L. Toward repurposing metformin as a precision anti-cancer therapy using structural systems pharmacology. Sci Rep. 2016;6:20441. doi: 10.1038/srep20441.

70. Strong R, Miller RA, Antebi A, Astle CM, Bogue M, Denzel MS, et al. Longer lifespan in male mice treated with a weakly estrogenic agonist, an antioxidant, an alpha-glucosidase inhibitor or a Nrf2-inducer. Aging Cell. 2016; doi: 10.1111/acel.12496.

71. Coyle C, Cafferty FH, Vale C, Langley RE. Metformin as an adjuvant treatment for cancer: a systematic review and meta-analysis. Ann Oncol. 2016;27(12):2184-95. doi: 10.1093/annonc/mdw410.

72. Coulston F, Dougherty WJ, LeFevre R, Abraham R, Silvestrini B. Reversible inhibition of spermatogenesis in rats and monkeys with a new class of indazol-carboxylic acids. Exp Mol Pathol. 1975;23(2):357-66.

73. Nath K, Guo L, Nancolas B, Nelson DS, Shestov AA, Lee SC, et al. Mechanism of antineoplastic activity of lonidamine. Biochim Biophys Acta. 2016;1866(2): 151-62. doi: 10.1016/j.bbcan.2016.08.001.

74. Magno L, Terraneo F, Bertoni F, Tordiglione M, Bardelli D, Rosignoli MT, et al. Double-blind randomized study of lonidamine and radiotherapy in head and neck cancer. Int J Radiat Oncol Biol Phys. 1994;29(1):45-55.

75. Carapella CM, Paggi MG, Calvosa F, Cattani F, Jandolo B, Mastrostefano R, et al. Lonidamine in the combined treatment of malignant gliomas. A randomized study. J Neurosurg Sci. 1990;34(3-4):261-4.

76. Schiffer D, Sales S, Soffietti R. Lonidamine in malignant brain tumors. Semin Oncol. 1991;18(2 Suppl 4):38-41.

77. Guo L, Shestov AA, Worth AJ, Nath K, Nelson DS, Leeper DB, et al. Inhibition of mitochondrial complex II by the anticancer agent Lonidamine. J Biol Chem. 2016;291(1):42-57. doi: 10.1074/jbc.M115.697516.

78. Nancolas B, Guo L, Zhou R, Nath K, Nelson DS, Leeper DB, et al. The anti-tumour agent lonidamine is a potent inhibitor of the mitochondrial pyruvate carrier and plasma membrane monocarboxylate transporters. Biochem J. 2016;473(7):929-36. doi: 10.1042/BJ20151120.

79. Paggi MG, Zupi G, Fanciulli M, Del Carlo C, Giorno S, Laudonio N, et al. Effect of lonidamine on the utilization of ${ }^{14} \mathrm{C}$-labeled glucose by human astrocytoma cells. Exp Mol Pathol. 1987;47(2):154-65.

80. Floridi A, Lehninger AL. Action of the antitumor and antispermatogenic agent lonidamine on electron transport in Ehrlich ascites tumor mitochondria. Arch Biochem Biophys. 1983;226(1):73-83.

81. Davidescu M, Macchioni L, Scaramozzino G, Cristina Marchetti M, Migliorati $\mathrm{G}$, Vitale $\mathrm{R}$, et al. The energy blockers bromopyruvate and lonidamine lead GL15 glioblastoma cells to death by different p53-dependent routes. Sci Rep. 2015:5:14343. doi: 10.1038/srep14343.

82. Nath K, Nelson DS, Heitjan DF, Leeper DB, Zhou R, Glickson JD. Lonidamine induces intracellular tumor acidification and ATP depletion in breast, prostate and ovarian cancer xenografts and potentiates response to doxorubicin. NMR Biomed. 2015;28(3):281-90. doi: 10.1002/nbm.3240.

83. Schmeisser S, Zarse K, Ristow M. Lonidamine extends lifespan of adult Caenorhabditis Elegans by increasing the formation of mitochondrial reactive oxygen species. Horm Metab Res. 2011;43(10):687-92. doi: 10.1055/s-0031-1286308.

84. Tommasino C, Gambardella L, Buoncervello M, Griffin RJ, Golding BT, Alberton $\mathrm{M}$, et al. New derivatives of the antimalarial drug Pyrimethamine in the control of melanoma tumor growth: an in vitro and in vivo study. J Exp Clin Cancer Res. 2016;35(1):137. doi: 10.1186/s13046-016-0409-9.

85. Levy JMM, Towers CG, Thorburn A. Targeting autophagy in cancer. Nat Rev Cancer. 2017;17(9):528-42. doi: 10.1038/nrc.2017.53.

86. Wang Z, Liu P, Chen Q, Deng S, Liu X, Situ H, et al. Targeting AMPK signaling pathway to overcome drug resistance for cancer therapy. Curr Drug Targets. 2016;17(8):853-64.

87. Yoshida GJ. Metabolic reprogramming: the emerging concept and associated therapeutic strategies. J Exp Clin Cancer Res. 2015;34(1):111. doi: 10.1186/s13046-015-0221-y.

88. Vitale I, Manic G, Dandrea V, De Maria R. Role of autophagy in the maintenance and function of cancer stem cells. Int J Dev Biol. 2015;59(1-3): 95-108. doi: 10.1387/ijdb.150082iv.

89. Yan Y, Xu Z, Dai S, Qian L, Sun L, Gong Z. Targeting autophagy to sensitive glioma to temozolomide treatment. J Exp Clin Cancer Res. 2016;35:23. doi: 10.1186/s13046-016-0303-5.

90. Li C, Liu Y, Liu H, Zhang W, Shen C, Cho K, et al. Impact of autophagy inhibition at different stages on cytotoxic effect of autophagy inducer in glioblastoma cells. Cell Physiol Biochem. 2015;35(4):1303-16. doi: 10.1159/ 000373952.

91. Choi DS, Blanco E, Kim YS, Rodriguez AA, Zhao H, Huang TH, et al. Chloroquine eliminates cancer stem cells through deregulation of Jak2 and DNMT1. Stem Cells. 2014;32(9):2309-23. doi: 10.1002/stem.1746.

92. Kimura T, Takabatake Y, Takahashi A, Isaka Y. Chloroquine in cancer therapy: a double-edged sword of autophagy. Cancer Res. 2013;73(1):3-7. doi: 10.1158/0008-5472.CAN-12-2464. 
93. Pascolo S. Time to use a dose of chloroquine as an adjuvant to anti-cancer chemotherapies. Eur J Pharmacol. 2016;771:139-44. doi: 10.1016/j.ejphar. 2015.12.017

94. Lee SW, Kim HK, Lee NH, Yi HY, Kim HS, Hong SH, et al. The synergistic effect of combination temozolomide and chloroquine treatment is dependent on autophagy formation and p53 status in glioma cells. Cancer Lett. 2015;360(2):195-204. doi: 10.1016/j.canlet.2015.02.012.

95. Hori YS, Hosoda R, Akiyama Y, Sebori R, Wanibuchi M, Mikami T, et al. Chloroquine potentiates temozolomide cytotoxicity by inhibiting mitochondrial autophagy in glioma cells. J Neuro-Oncol. 2015;122(1):11-20. doi: 10.1007/s11060-014-1686-9.

96. Rosenfeld MR, Ye X, Supko JG, Desideri S, Grossman SA, Brem S, et al. A phase I/II trial of hydroxychloroquine in conjunction with radiation therapy and concurrent and adjuvant temozolomide in patients with newly diagnosed glioblastoma multiforme. Autophagy. 2014;10(8):1359-68. doi: 10 4161/auto.28984.

97. Briceno E, Reyes S, Sotelo J. Therapy of glioblastoma multiforme improved by the antimutagenic chloroquine. Neurosurg Focus. 2003; 14(2):e3.

98. Sotelo J, Briceno E, Lopez-Gonzalez MA. Adding chloroquine to conventional treatment for glioblastoma multiforme: a randomized, doubleblind, placebo-controlled trial. Ann Intern Med. 2006;144(5):337-43.

99. Briceno E, Calderon A, Sotelo J. Institutional experience with chloroquine as an adjuvant to the therapy for glioblastoma multiforme. Surg Neurol. 2007; 67(4):388-91. doi: 10.1016/j.surneu.2006.08.080.

100. Golden EB, Cho HY, Hofman FM, Louie SG, Schonthal AH, Chen TC. Quinoline-based antimalarial drugs: a novel class of autophagy inhibitors. Neurosurg Focus. 2015;38(3):E12. https://doi.org/10.3171/2014.12. FOCUS14748.

101. Lee MS, Johansen L, Zhang Y, Wilson A, Keegan M, Avery W, et al. The novel combination of chlorpromazine and pentamidine exerts synergistic antiproliferative effects through dual mitotic action. Cancer Res. 2007;67(23): 11359-67. doi: 10.1158/0008-5472.CAN-07-2235.

102. Shin SY, Lee KS, Choi YK, Lim HJ, Lee HG, Lim Y, et al. The antipsychotic agent chlorpromazine induces autophagic cell death by inhibiting the Akt/ mTOR pathway in human U-87MG glioma cells. Carcinogenesis. 2013;34(9): 2080-9. https://doi.org/10.1093/carcin/bgt169.

103. Dolma S, Selvadurai HJ, Lan X, Lee L, Kushida M, Voisin V, et al. Inhibition of dopamine receptor D4 impedes Autophagic flux, proliferation, and survival of glioblastoma stem cells. Cancer Cell. 2016;29(6):859-73. doi: 10.1016/j. ccell.2016.05.002.

104. Fan Q, Aksoy O, Wong RA, Ilkhanizadeh S, Novotny CJ, Gustafson WC, et al. A kinase inhibitor targeted to mTORC1 drives regression in glioblastoma. Cancer Cell. 2017;31(3):424-35. doi: 10.1016/j.ccell.2017.01.014.

105. Tanaka K, Sasayama T, Irino Y, Takata K, Nagashima H, Satoh N, et al. Compensatory glutamine metabolism promotes glioblastoma resistance to mTOR inhibitor treatment. J Clin Invest. 2015;125(4):1591-602. doi: 10.1172/ JCl78239.

106. Ward PS, Thompson CB. Metabolic reprogramming: a cancer hallmark even Warburg did not anticipate. Cancer Cell. 2012;21(3):297-308. doi: 10.1016/j. ccr.2012.02.014.

107. Cairns RA, Harris IS, Mak TW. Regulation of cancer cell metabolism. NatRevCancer. 2011;11(2):85-95. doi:nrc2981 [pii];doi: 10.1038/nrc2981 [doi].

108. Pedersen PL. Warburg, me and hexokinase 2: multiple discoveries of key molecular events underlying one of cancers' most common phenotypes, the "Warburg effect", i.E., elevated glycolysis in the presence of oxygen. J Bioenerg Biomembr. 2007;39(3):211-22. doi: 10.1007/s10863-007-9094-X.

109. Floridi A, Paggi MG, Fanciulli M. Modulation of glycolysis in neuroepithelial tumors. J Neurosurg Sci. 1989;33(1):55-64.

110. Paggi MG, Fanciulli M, Del Carlo C, Citro G, Carapella CM, Floridi A. The membrane-bound hexokinase as a potential marker for malignancy in human gliomas. J Neurosurg Sci. 1990;34:209-13.

111. Zhou Y, Zhou Y, Shingu T, Feng L, Chen Z, Ogasawara M, et al. Metabolic alterations in highly tumorigenic glioblastoma cells: preference for hypoxia and high dependency on glycolysis. J Biol Chem. 2011;286(37):32843-53. doi: 10.1074/jbc.M111.260935.

112. Hanahan D, Weinberg RA. Hallmarks of cancer: the next generation. Cell. 2011;144(5):646-74. doi: 10.1016/j.cell.2011.02.013.

113. Roberts DJ, Tan-Sah VP, Ding EY, Smith JM, Miyamoto S. Hexokinase-II positively regulates glucose starvation-induced autophagy through TORC1 inhibition. Mol Cell. 2014;53(4):521-33. doi: 10.1016/j.molcel.2013.12.019.
114. Sanduja S, Feng Y, Mathis RA, Sokol ES, Reinhardt F, Halaban R, et al. AMPK promotes tolerance to Ras pathway inhibition by activating autophagy. Oncogene. 2016:35(40):5295-303. doi: 10.1038/onc.2016.70.

115. YL H, DeLay M, Jahangiri A, Molinaro AM, Rose SD, Carbonell WS, et al. Hypoxia-induced autophagy promotes tumor cell survival and adaptation to antiangiogenic treatment in glioblastoma. Cancer Res. 2012;72(7):1773-83. doi: 10.1158/0008-5472.CAN-11-3831.

116. Talarico C, Dattilo V, D'Antona L, Menniti M, Bianco C, Ortuso F, et al. SGK1, the new player in the game of resistance: chemo-radio molecular target and strategy for inhibition. Cell Physiol Biochem. 2016;39(5):1863-76. doi: 10 1159/000447885.

117. D'Antona L, Amato R, Talarico C, Ortuso F, Menniti M, Dattilo V, et al. SI113, a specific inhibitor of the Sgk1 kinase activity that counteracts cancer cell proliferation. Cell Physiol Biochem. 2015;35(5):2006-18. doi: 10.1159/ 000374008.

\section{Submit your next manuscript to BioMed Central and we will help you at every step:}

- We accept pre-submission inquiries

- Our selector tool helps you to find the most relevant journal

- We provide round the clock customer support

- Convenient online submission

- Thorough peer review

- Inclusion in PubMed and all major indexing services

- Maximum visibility for your research

Submit your manuscript at www.biomedcentral.com/submit

) Biomed Central 